\title{
Teaching a biology laboratory course using Dictyostelium
}

\author{
DAVID A. KNECHT ${ }^{*}, 1$, KATE M. COOPER ${ }^{2}$ and JONATHAN E. MOORE ${ }^{3}$ \\ ${ }^{1}$ Department of Molecular and Cell Biology, University of Connecticut, Storrs, CT, ${ }^{2}$ Division of Molecular, Life, and \\ Health Sciences, Loras College, Dubuque, IA and ${ }^{3}$ Biology Department, Pomona College, Claremont, CA, USA
}

\begin{abstract}
The Dictyostelium discoideum model system is a powerful tool for undergraduate cell biology teaching laboratories. The cells are biologically safe, grow at room temperature and it is easy to experimentally induce, observe, and perturb a breadth of cellular processes making the system amenable to many teaching lab situations and goals. Here we outline the advantages of Dictyostelium, discuss laboratory courses we teach in three very different educational settings, and provide tips for both the novice and experienced Dictyostelium researcher. With this article and the extensive sets of protocols and tools referenced here, implementing these labs, or parts of them, will be relatively straightforward for any instructor.
\end{abstract}

KEY WORDS: teaching, education, chemotaxis, cell biology, microscopy

\section{Introduction}

Undergraduate institutions are under constant pressure to cut costs, and laboratory courses are a frequent target. Yet the importance of laboratory experiences in the biological sciences are clear to those of us who teach them and from the feedback of students we have taught. Done well, these laboratories can introduce students to both the natural world and the process of doing scientific research. Many students have an interest in research, while others have no idea what that means, and a properly designed course may either encourage them to continue down that educational pathway or having been exposed, they will have a better understanding of why they are not interested in research. In either case, the course will be enriching for the student's overall education.

Choosing and designing teaching labs involves compromise. Balancing learning goals, instructional time, student preparedness, pre-lab set-up and preparation time, budget realities, facilities and equipment, and the instructors' and staffs' expertise create a variety of challenges. Using Dictyostelium discoideum (hereafter referred to as Dictyostelium) and other soil amoebae as a teaching model opens a wealth of opportunities for laboratory courses which focus on a research experience for undergraduates. There are many advantages of using these cells, and it is feasible to implement such a course with a relatively low-cost investment. More importantly, working with Dictyostelium requires little experience as exemplified by two of the authors of this chapter, who were Dictyostelium novices when they started their teaching labs. We hope to provide the benefit of our experience in creating laboratory courses and modules using Dictyostelium to help others if they choose to develop similar courses. With the information in this chapter and the tools available through dictyBase (www. dictybase. org) no instructor should be intimidated to use Dictyostelium cells in their laboratory class.

We will first outline the advantages of using Dictyostelium amoebae in a teaching laboratory. We will then individually show how Dictyostelium allows us to achieve the goals of our three laboratory courses: a small (12 students) semester long intensive research lab course, a 110-student introductory inquiry-based lab course with a 7-week Dictyostelium module, and a 30-student upper-level lab course with a 2-week Dictyostelium module. The remaining two sections provide advice for the Dictyostelium novice setting up a teaching lab and cost cutting tips.

\section{Advantages of using Dictyostelium in a biology or cell biology teaching lab}

- Cells are inexpensive to grow in large quantities and they are not fastidious in culture. They can be grown on surfaces or suspension to high densities with minimal sterility concerns.

- The cells are happy in the same environment as humans. There is little need for special chambers, media or $\mathrm{pH}$ or temperature control systems.

- They are visually stimulating. A variety of types of experiments using live cells are feasible within the time constraints often

Abbreviations used in this paper: GFP, green fluorescent protein.

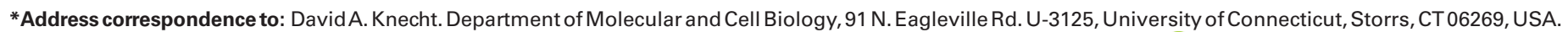

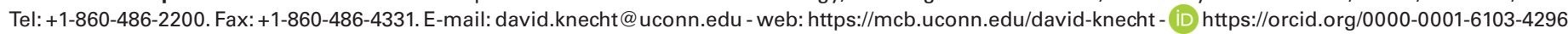

Supplementary Material (four movies) for this paper is available at: https://doi.org/10.1387/ijdb.190249dk

Submitted: 8 June, 2019; Accepted: 9 July, 2019.

ISSN: Online 1696-3547, Print 0214-6282 
present in a teaching lab. The activity of cells can be visualized in real time with a simple microscope.

- Their unusual, but easily understood life cycle can be related to a variety of basic cell biological concepts (see Bozzaro, 2019).

- They allow hypothesis-driven experiments with complicated ideas that can be executed in a three-hour time frame. Many of these cell biology experiments can be related back to questions of human disease which increases student interest.

- Many toxic and expensive substances can be used by students because of the small quantities of the substance they will need.

- Dictyostelium has a long history as a model organism. When it comes to student projects, this means that the literature is extensive yet less overwhelming than that of many other and more well-known model organisms.

- The worldwide community of Dictyostelium researchers is accessible and responsive through a listserv maintained in dictyBase and wonderfully helpful, especially to newcomers to the system.

- There are also extensive resources, protocols and general information available on dictyBase.

\section{Scenario 1: University of Connecticut Cell Biology Laboratory (MCB 2225)}

A semester long intensive research laboratory course with support services available. Limited to twelve students per semester ranging from freshmen to seniors. The course is run by the Instructor plus one Teaching Assistant two afternoons a week with open lab access at other times. Protocols for each experiment on dictyBase (http://dictybase.org/teaching_tools/index.html) or MCB 2225 web site (cellbiolab.mcb2225.uconn.edu). PowerPoint versions of associated lectures also available there.

\section{Motivation}

This course was developed because I found undergraduate students to be an energetic and motivated source of labor in the research lab. Honors students in particular were required to do a research project and so wanted to find a laboratory to join. However, there are far more students professing interest in working in a lab than our department could accommodate. Over the years, it became clear that a number of issues made it difficult for undergraduate students to contribute to the goals of the lab in a way that justified the time and expense.

1. Many of the students were ill prepared for the research experience.

2. Some students found that they did not enjoy the drudgeries and frustrations of research once they were exposed to what laboratory science was all about.

3. Training of students who wanted to work in my lab required a great deal of time from graduate students, post-docs and technicians.

The new laboratory course was designed whose goals were:

1. Mimic the environment of a research laboratory to give students an idea of what doing laboratory research is like while they learn some broadly applicable skills. A key requirement was for the students to have $24 / 7$ access to the lab so that they could work on projects and experiments as needed, rather than be limited to the 3-hour standard laboratory time block. The semester would culminate in an independent project that would allow students the freedom to delve into a topic in more detail.
2. Allow the students to have freedom to design their experiments within a guided framework, but require them to focus on a question, write a protocol, implement the protocol and then analyze the data.

3. Use live cells (Dictyostelium) and video microscopy as a focus for visualizing cell structure and function. In my lecture class, it was clear that students found video microscopy exciting and accessible so I suspected that students would be excited at the prospect of creating time-lapse movies themselves.

4. Make the course cost effective. We had previously offered a Cell Culture course working with mammalian cells, but the complexity and cost of incubators, media, hoods etc. made the course too expensive to offer routinely to undergraduates. Since my lab worked on Dictyostelium, it was clear that a course using live Dictyostelium cells imaged at ambient temperature eliminated much of the complexity of mammalian cells while accomplishing most of the same cell biology pedagogical goals.

5. Have graduate students working from my lab gain experience as Teaching Assistants for the course, allowing them to bring aspects of their research projects to the course.

The course has evolved over the 14 years it has been taught. Most of the undergraduates who have worked in my laboratory have come from this course. Many students joined other labs based on the skills they learned in the course. Many students that did not think they were interested in research as a career, changed their trajectory as a result of this semester long experience. Some students found out that they really did not like working in a lab and changed goals as a result.

Two factors I believe are especially important in the success of this course:

First is the progression of skills that all students must master. For instance, because students must maintain their own cells throughout the semester, they become invested in learning the skills they need. They cannot say to themselves, "This is hard but we will move on so I am OK not being good at this". The techniques they learn at the beginning are used over and over again so that even those who struggle initially to master good sterile technique or harvest cells from a dish or use a microscope, are masters of these techniques by the end and take pride in having acquired those skills.

The second factor is the open lab access. If an experiment does not work, students can come in at whatever time fits their schedule and repeat the experiment until they get it right.

\section{Resources}

We have a dedicated staff that prepares materials and purchases supplies for all of our undergraduate laboratory classes. One staff group handles the large numbers of students in introductory laboratories and an overlapping group supports the smaller, more advanced lab courses such as this one. In the beginning, my research laboratory provided nearly all the routine reagents for the course and the lab staff purchased plasticware and special reagents specifically for class use. Over time, by using commercial powdered medium from Formedium, Inc. (https://www.formedium. com/product-category/formedium-media/dictyostelium-discoide$\mathrm{um} /$ ) and plasmid isolation kits, the staff now makes nearly all the reagents for the course and this transition has presented no problems. My research laboratory still provides the cell lines from our $-80^{\circ} \mathrm{C}$ stored stocks but it would not be difficult for the staff to 
do that as well.

We have 6 pairs of students at 6 lab benches, each with pipetters and a small inverted tissue culture microscope. The students work in pairs for the first part of the semester and then on their own for the last month. Side benches hold accessory equipment (shakers, electroporator, balance, microwave, centrifuges). There are three small semi-dark rooms off the main lab housing 6 microscope/ computer workstations. It turns out that the rooms do not need to be very dark in order to do fluorescence microscopy. If overhead light in the small rooms is turned off, light coming from the main lab does not increase the background significantly.

Students are given keys to the building and safety instructions for after-hours work. While there might be concerns about security, we have never had a problem. We have one Teaching Assistant plus the instructor who are present throughout the normal lab time to help and answer questions. We have found that a group social media communication system is a great tool for fostering collaboration. We use GroupMe and enroll everyone in the class so they can post messages to each other and the instructors outside of class time. The students often solve each other's problems without the instructors needing to get involved.

\section{Major equipment}

An NSF CCLI grant funded the purchase the equipment for the course, including 6 Nikon TI inverted microscopes, CCD cameras and iMac computers. I built LED illuminators for transmitted light and two channels of fluorescence using Thorlabs parts (see cellbiolab. mcb2225.uconn.edu for construction details). The microscopes have $4 \mathrm{x}, 10 \mathrm{x}, 20 \mathrm{x}, 40 \mathrm{x}$, and 100x oil immersion objectives, all with phase contrast. The $4 x, 10 x$ and $100 x$ get most of the use so a smaller objective set is feasible. Each microscope has a CCD or CMOS camera interfaced with a computer and the image acquisition and analysis are all done through the ImageJ (https:// fiji.sc) and the equipment control plugin, Micro-manager (https:// micro-manager.org). The worldwide support group and open source nature of this platform helped to keep costs down. My goal was to build these systems as inexpensively as possible with the most capabilities for experiments. The microscopes cost about $\$ 15,000$ each; cameras were about $\$ 1500$, computers about $\$ 1500$. The 3 channel LED illuminators were built from Thorlabs parts for about $\$ 2000-3000$ each. Thus each workstation was about $\$ 20,000$ each with 2 channels of fluorescence, phase contrast objectives and a range of magnifications. We also built one system around a Nikon TS-100 small tissue culture microscope as a more transportable system. This microscope system has nearly equal capabilities but cost about $\$ 12,000$.

\section{Cost of consumables}

The cost of running the lab for a semester is about $\$ 175 /$ student which includes Petri dishes, pipettes and other consumables. The purchase of specialized reagents including antibodies, dyes, inhibitors etc. can raise the cost to about $\$ 250 /$ student.

\section{Lecture vs. Lab}

The course normally is scheduled for T/Th from $1 \mathrm{PM}$ to $5 \mathrm{PM}$. We meet for about an hour to discuss issues from the past week and to introduce the next topic, before moving to the laboratory. Students are told they can come and go as they need. Lecture may also include information on Dictyostelium, microscopy, software, image analysis, or the biological process they will be examining in their experiments. They are expected to have read the experimental outline before class and a quiz is given at the beginning of class before each new experiment is started. As the semester proceeds, I lecture less often in order to maximize the time they have in the lab. The students work in pairs for $2 / 3$ of the semester, with each pair having a bench and a microscope work station. The last third of the course is devoted to independent projects. Students present a weekly update to the class on their projects in order to develop presentation skills and get feedback from the rest of the class.

\section{Prerequisites}

Initially, I implemented the course with a prerequisite of our Cell Biology lecture course. However, I also wanted to give students this lab research experience early in their academic career. I eventually realized that since the focus was how to learn about laboratory experimental science, the students did not need much background in Cell Biology. In Introductory Biology, they learned enough about cell structure and function to be able to understand the experiments and in my lectures, I was teaching everything specific to the experiments that they need to know. Therefore, the prerequisites were changed to require only Introductory Biology. That opened the course to freshmen who had taken Introductory Biology in high school as well as second semester freshman and sophomores. This has been a generally successful change, but some students struggle as they are still adapting to college life and the discipline necessary to be successful. However, the lack of Cell Biology coursework has not been an issue. There are still many students who sign up for the class in their last semester in college in order to fulfill their laboratory requirement for the major. Some of these students are just fulfilling a requirement for their major, however, a significant number of these students find that they really enjoy research and find jobs in a science related area. It has been rewarding to have altered the career trajectory of a significant proportion of students who have passed through the course.

\section{Overall learning goals}

The design of the course and the open access to the lab has had some important unintended consequences. Since the students are treated as adults who are responsible for their cells and experiments, they take ownership of their education in ways not normally available to them. They are not just taking the class; they are participating in the educational process. For many, this is the first time they are treated as intelligent, capable adults and not just "students," and that turns out to be a huge motivation. Many students spend hours in the lab outside of class time by choice because they enjoy the fact that they are doing and learning and the answers to the questions they are asking are not "known". It is also important that there are no "right" answers to the questions they are asking. They cannot look up the answers on the internet and it is stressed to them that there is no right answer, only the analysis of the data they acquire.

What has surprised me is the frequency with which I have been told that this course is the best or most impactful course they have taken as undergraduates. The reason differs with the student, but I think overall it is the freedom to explore and learn at their own pace in a supportive environment. Most importantly, they learn there are no endpoints as each question leads to a new one. By 


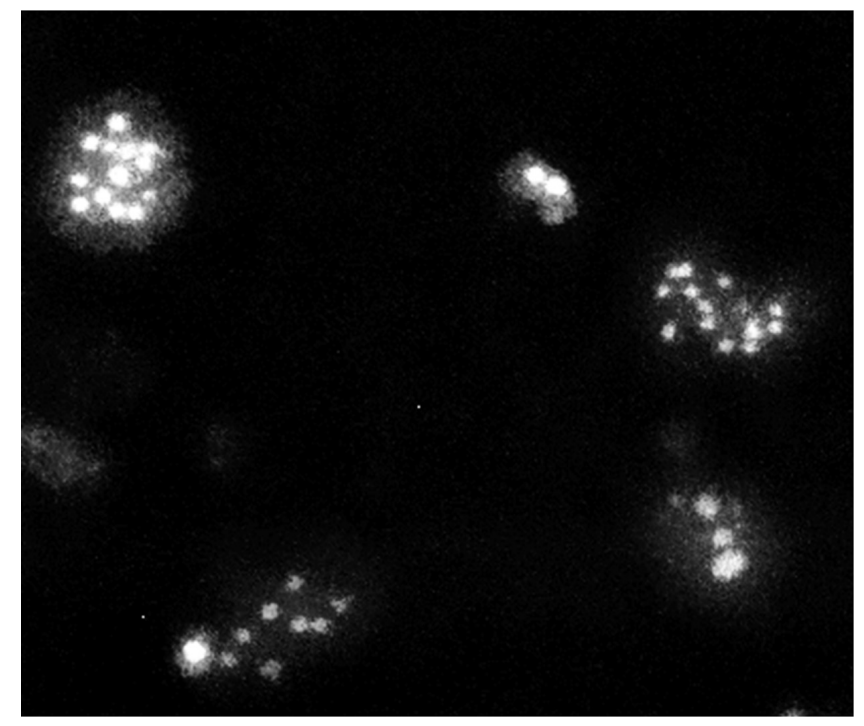

Fig. 1. Cells lacking Myosin II and expressing a fluorescent nuclear probe grown in suspension for 3 days become multi-nucleated.

the end of the semester, they are confident in the skills they have acquired, have produced some new knowledge and have a feeling of accomplishment.

\section{Course timeline and learning goals of each module}

\section{Weeks 1,2: cell growth}

This section teaches a number of important skills. Students must become adept at sterile technique as they maintain their cultures of axenic cells in a complex liquid medium (HL5: recipe at http:// dictybase.org/techniques/media/media.html\#HL5) throughout the semester. They learn to triturate cells, use a hemocytometer, and plot a growth curve to see the difference between a linear plot and a semi-log plot. They should learn what part of their data is exponential growth and which part is stationary phase. This is an important first lesson in analysis of data. Despite clear instructions, students frequently plot all of their data to calculate a doubling time, which results in an incorrectly long doubling time. To do this analysis correctly, the students have to look at the data and realize that not all of it will not be linear on an exponential plot and then they use judgement to determine which data to include to get a best fit to an exponential function. This alerts students to the fact that thinking is required.

An added element is the comparison of wild-type and myosin II mutant cell (HK321) growth. The starting point is reminding students that they have learned that myosin II is found in the cleavage furrow of cells and is hypothesized to be important for cytokinesis. But since we are giving them cells that lack myosin II, it is obviously not a lethal mutation. I use this as one of many examples of the limitations of the core information that they learn in a textbook lecture course. What they were taught is not "wrong", but the real answer is more nuanced and depends on many factors. What is the phenotype? Growing cells in Petri dishes, the students find that both wild-type and mutant grow with a similar generation time. In parallel, they grow the two strains in flasks on a shaker. There they find that the mutant cells do not increase in number but just get larger. Next, we image the cells expressing a fluorescent nuclear probe (td-Tomato-NLS expression) or fix and stain with propidium iodide and the cells grown in shaking suspension are spectacularly large (they quantify the size/volume) and have many nuclei (Fig. 1). These observations allow the students to tie together the lack of growth in suspension with the cytokinesis defect. They learn that the defect in myosin II mutant cells is conditional; cells can divide when attached to a surface, but not when grown in suspension.

If resources or time are limited the growth section can be eliminated or shortened. If students are not going to maintain cultures, it would still be useful for them to learn to use a hemocytometer and do the calculations necessary to adjust cell densities for a given experiment. One simple experiment that requires few resources is to have students plate amoebae for clonal growth and development. If SM agar plates (http://dictybase.org/techniques/ media/media.html\#HL5) and a culture of Klebsiella aerogenes are provided to the students, then the goal is to plate 5 or 50 amoebae on a plate so that each amoeba grows to create a plaque in the bacterial lawn and then cells begin to develop within the plaque. It is always interesting to watch students struggle with the calculations and dilutions necessary to go from a $1 \times 10^{6}$ cells $/ \mathrm{ml}$ culture to putting 5 cells on a plate (see Development, part 3 protocol). To make this experiment even more interesting, comparing growth and development of myosin II null mutant cells to wild type shows unexpected phenotypes. The mutant plaques appear days after the wild type and spread very slowly. In addition, the mutant only develops to the mound stage.

\section{Weeks 2,3: random cell motility}

This experiment overlaps with cell growth. While they are collecting data on growth, they begin using the microscope workstations to image growing cells. Analyzing and quantifying cell motility is a very versatile and flexible lab exercise for students. My course has students collect data from video microscopes that they then analyze. The students are given a wide range of options to investigate. They have wild-type and mutant cells to compare as a baseline. They then can put the cells on different surfaces including plastic, poly-L-lysine coated plastic, protein-coated plastic (BSA etc.) glass coverslips that can be put into the plastic dish (allowing both surfaces to be recorded), acid washed glass coverslips, protein coated glass coverslips, or agarose added to the bottom of the plastic dish. The cells can be put into buffer or medium or buffer plus bacteria. The students need to think about the question they are going to ask and the controls they need to do depending on the experiment and the details that might not be obvious. Are they going to start collecting data as soon as the cells are put into the dish? Does it matter? Do the cells immediately begin moving and is that movement the same over time? Does the movement change if you look after an hour or after a day? How do you do multiple conditions and have them be as comparable as possible? How do you do multiple cell types and make the conditions as comparable as possible.

We then use the mTrackJ plugin to ImageJ to track cells and measure speed, distance, direction, and turning (Fig. 2). We tend to focus on speed and persistence for our analysis. One simple measure of persistence is to compare the total distance moved to the net distance moved. The more a cell turns randomly, the less its net distance will be relative to its total distance. This can also be quantified as the average angular change in direction of movement over time. We have not focused on the statistical analysis of the 


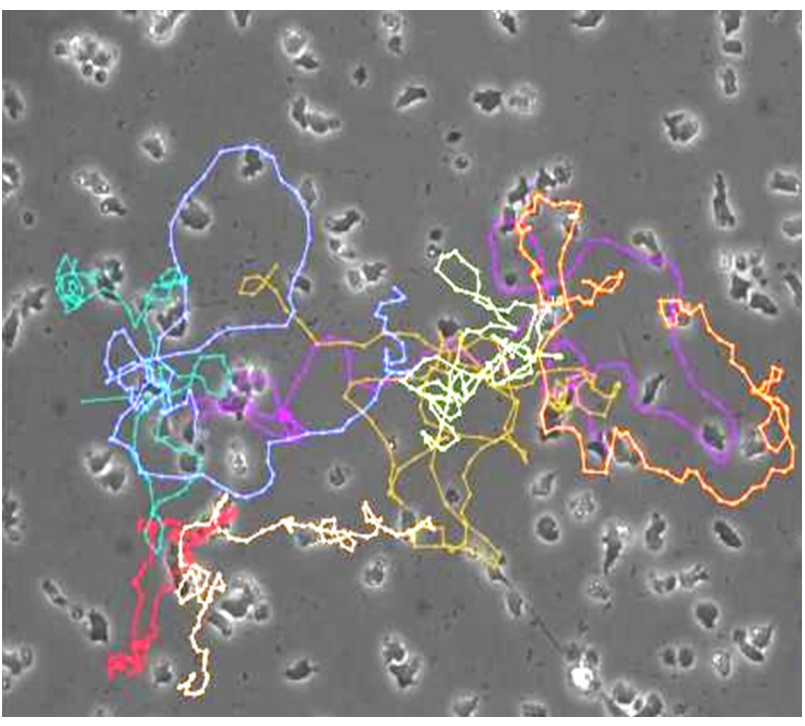

Fig. 2. Tracks of cells moving randomly during growth.

data, but that is another aspect that can be added.

If a fluorescence microscope is available, one can combine quantification of motility parameters with cell dynamics associated with movement. Cells expressing a lifeact-GFP probe allows visualization of changes in F-actin localization over time. The cells are very sensitive to fluorescent light exposure, so the key to reducing phototoxicity is to use long exposures (300-500 ms) with as low light exposure as possible. ADIC equipped microscope allows visualization of pseudopods and vesicle movement inside cells. With this addition, students can describe the ultrastructural changes that occur associated with cell motility.

All of these complexities of analysis from a simple time lapse dataset provide an ideal opportunity to explore the nuances of data analysis. It challenges students to formulate clear and narrow questions, figure out appropriate controls and think about how to quantify data to answer the questions they have posed.

There are many ImageJ plugins and other software that will do image analysis and motility quantification, but we find the mTrackJ plugin to be robust and provides a wealth of data. Students are encouraged to first spend time watching the time lapse videos to begin to think about what they are going to quantify. For instance, if the cells are stationary for some time when first settling to the bottom, and then begin to move, they can quantify the speed of movement over time to see how it changes and if it stabilizes. Alternatively, they might standardize on analyzing for a period of time 1 hour after plating. Another question is where to click to identify a cell position. Should you click the front, the back, or the center? The frame interval of clicking on cells is a deceptively complicated issue. If the frame interval is short and the cells don't change position significantly in that interval, then there is a problem of trying to accurately click in the same place repeatedly. If the position is slightly off, the software identifies that as movement and calculates a speed. If the interval is too long relative to the translocation of the cell, some of the cell movement is missed. If one plots the frame time interval vs. speed, you can show that there is a sweet spot where average speed plateaus because you are quantifying the "translocational speed". If the frame interval is increased further, the average speed will decrease because some translocation is not measured.

The next question the students must decide how to pick the cells to analyze. Does it matter if each cell is tracked for the same time interval? If some cells move and some cells do not move, do you analyze both and average (i.e. how do you deal with a bimodal or multi-modal population)? Cells will periodically divide during the capture, so how do you analyze those cells?

\section{Week 4}

Transfection: Electroporation of cells with transfection vectors expressing GFP and RFP probes. The current protocol is very robust and we are nearly always successful generating transfected cells that can be used for further experiments. A wide range of vectors are available from dictyBase in addition to the ones described here. The dishes are periodically imaged to show the drug selection process. Once the transfected cells are available (about 1 week) they are imaged to show the localization or lack of localization of the probes. The students continue to culture these cells for future experiments.

\section{Week 5: chemotaxis to folic acid}

Folate chemotaxis allows students to compare and contrast chemotactic motility to random motility. In the soil, bacteria are the natural food source for amoebae, and cells respond to folic acid produced by bacteria and migrate directionally toward them. Using folic acid in a chemotaxis assay, students can measure the directional movement of cells toward the folate source and compare that movement to random cell movement. The assays are quite
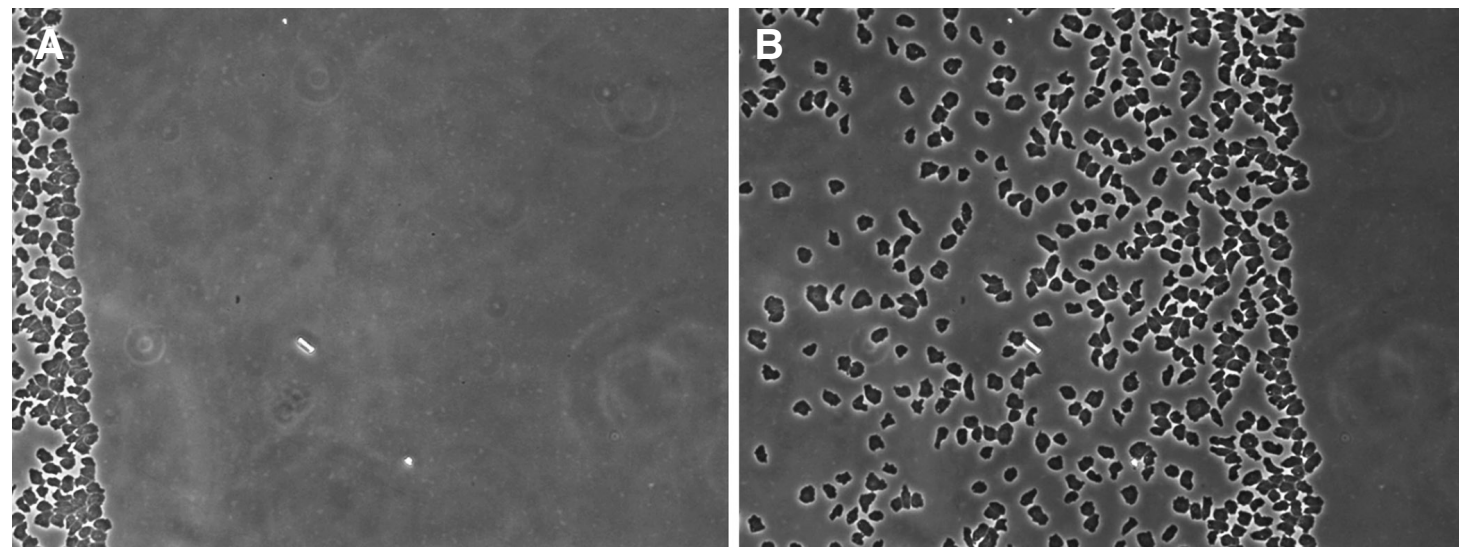

Fig. 3. Under agarose chemotaxis assay at beginning (A) and after 3 hours (B). The folic acid well is off screen to the right and cells migrate from left to right over time. 


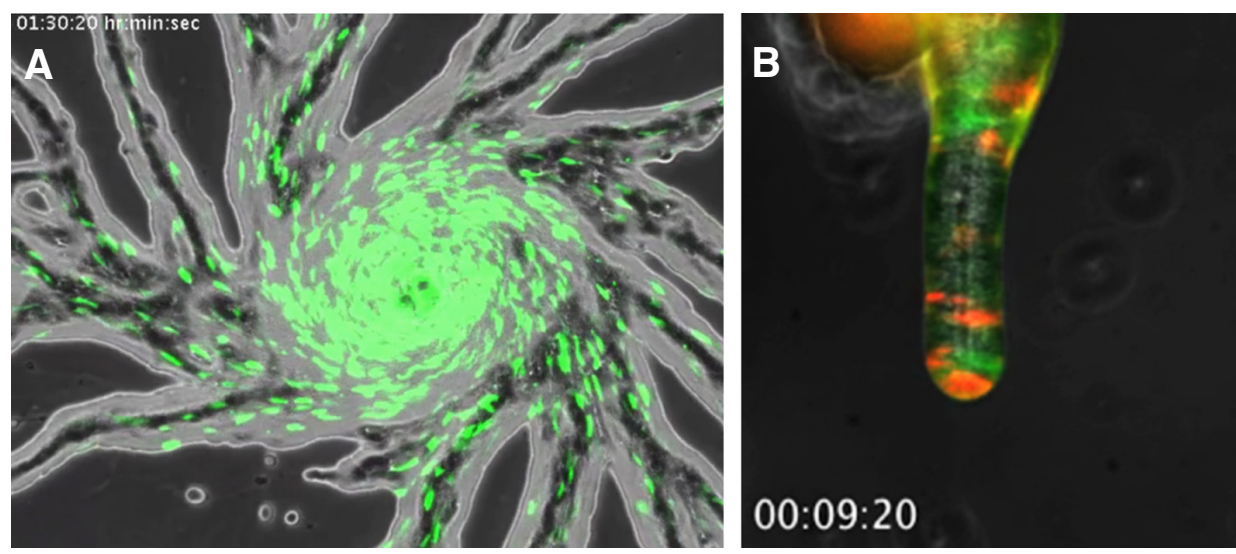

Fig. 4 (A) GFP expressing cells in aggregation streams. (B) GFP and RFP expressing cells in a chimeric slug.

robust and a variety of approaches are possible for either under agarose or over agarose assays. In the subsequent sections, the use of this assay for larger class formats with less equipment requirements is discussed.

In the under-agarose assay, two wells are cut in an agarose sheet in a Petri dish and cells are added to one well and folate to the other well (Laevsky and Knecht, 2001). The agarose stabilizes the folate gradient and the cells move on the plastic underneath the agarose toward the folate source. Time lapse images can be captured with an inverted microscope to measure individual cell movements (Fig. 3 and Supplemental Movie 1). Alternatively, data can be collected on an upright microscope or as an endpoint assay (see Scenario 2 and 3).

Another option is doing the assay where the cells are on top of the agarose. Droplets of cells are placed around a circular well cut in the agarose and with filled with folic acid. The cell movement toward the folate well can be visualized in time lapse or using a stereo microscope as an endpoint assay (see Nelson or Soldati chemotaxis protocols: http://dictybase.org/teaching_tools/index.html).

All of the same analysis can be conducted as described above for random motility, allowing for comparison of the two types of motility (if time lapse is used). Even if an endpoint assay is used it is possible to compare the control with the response to folate.

Chemotaxis to cAMP is also possible, but this complicates the assay. Cells need to be starved for 8-12 hours to become responsive to cAMP plus cells produce their own cAMP. Thus we find it simpler for teaching situations to focus on folic acid chemotaxis, but protocols are available on dictyBase for lab experiments that perform cAMP chemotaxis.

\section{Weeks 6,7: Development}

Imaging the process of development is inherently interesting as an example of a simple differentiation and morphogenesis process with the same underlying gene regulation and cell movement/ shape questions as embryonic development. In order to provide a link to the previous experiments we compare the development of wild-type and myosin II mutant cells. With the availability of fluorescence time lapse microscopes, we can also provide a link to the motility analyses already done. We developed the chimeric aggregation assay as a way to analyze movements of cells undergoing collective cell migration. Since individual cells are difficult to identify during multicellular development, fluorescently labeling and tracking a small population of cells within the organism allows individual cell behavior to be analyzed and compared to the other forms of motility discussed above.

In Week 4, cells were transfected by electroporation with GFP or mCherry probes. With those cells either made by the students or given to them by the instructor, the experiment is set up either over buffered agarose or under buffered agarose using $2 \%$ GFP wild-type and $2 \%$ mCherry mutant mixed with $96 \%$ unlabeled wild-type cells to compare the behavior of each cell type in an otherwise wild-type environment. One can also mix the same fluorescent populations with $96 \%$ unlabeled mutant cells to ask how each cell type behaves in a mutant environment. The under-agarose experiment is ideal for analyzing cAMP chemotaxis and streaming of cells to form aggregates. A monolayer under agarose robustly aggregates in about 10-12 hours and the flattening of the cells by the agarose increases the contrast of the images. Early in aggregation, cAMP waves move through the field of cells and that causes a change in cell shape that can be seen in phase contrast. By measuring the average pixel intensity of a region of the image over time, it is possible to measure the cAMP pulse rate (about 7 minutes) as changes in the average intensity. However, the cells only develop to the aggregate stage under agarose. The over agarose development is more difficult to set up (cells do not stick to agar well so very gentle handling is necessary), but all stages of development can be imaged (Fig. 4 and Supplemental Movies 2 and 3). If a confocal microscope is available, 4D imaging of cells throughout development is also possible.

\section{Optional experiments depending upon the student group}

Sometimes the prior experiments go slowly so we do not always get to experiments from weeks 8 and 9 .

\section{Week 8}

Endocytosis by imaging and flow cytometry: Cells are incubated with fluorescent dextran to measure uptake of fluid phase by endocytosis (mostly macropinocytosis in axenic strains). Samples are taken over time and the fluorescence intensity increase is measured with the flow cytometer in our core facility. In parallel, the students image the cells over time to determine the location of the probe in cells and to see if they can quantify the uptake and compare it to the cytometry measurements.

\section{Week 9}

Fixation, immunostaining and 3D imaging of amoebae cytoskeleton: If a fume hood is available, it is possible to fix and stain cells in a class period. This turns out to be a challenging experiment because amoebae do not adhere well to glass surfaces so it takes very gentle handling to not lose the cells in the course of all the incubations and washes. It helps to use acid washed coverslips, or multi-well dishes, but it is difficult to communicate the importance of gentle handling, so many students have very few amoebae that are hard to find at high magnification by the time they are done. This is a challenging experiment for beginners in the lab. The use 
of live cells expressing fluorescent probes is an alternative way to introduce students to cell structures.

\section{Weeks 10-14: independent projects}

Students have done a variety of independent projects over the years. Many projects have been offshoots of PhD student projects. Recently, we have adopted a different paradigm which would work especially well for instructors less experienced with Dictyostelium. In one iteration, we have ordered less well studied species of amoebae (see Romeralo et al., 2013,) from dictyBase Stock Center. Students learn to grow cells in association with bacteria (these species will not grow in HL5 medium) and then they can apply all the skills they have learned; measuring growth rate, imaging cytokinesis, and measuring random and chemotactic motility. They then attempt to transfect the cells with GFP and RFP vectors to see if promoter function is shared with Dictyostelium. This also requires them to test whether the cells are resistant to standard antibiotics. They can also attempt to derive an axenic variant of the cells. Depending on the species, they can also see if the new species co-develops with the non-axenic wild-type NC4 cell line using the chimeric aggregation assay with fluorescently labelled cells to track each species. If the cells cannot be transfected, CellTracker Green ${ }^{\mathrm{TM}}$ has labelled every species of amoebae we have tested (protocol on dictyBase).

Alternatively, each student collects several samples of soil from the local environment and then isolates amoebae from the samples. They then characterize the strains they find and compare them to the standard NC4 cell line. Almost every sample has yielded an amoebal cell line to study and sometimes more than one species. There are a lot more predatory amoebae in the soil than I ever imagined. Some are similar to Dictyostelium in being social amoebae that aggregate and form fruiting bodies, but many are very different. We are considering having DNA sequenced from each isolate in the future.

Below are other experiments we have done for which there are protocols posted on dictyBase (http://dictybase.org/teaching_tools/ index.html and http://mcb2225.uconn.edu)

\section{Phagocytosis}

Silica particles or heat-killed yeast can be used to image phagocytosis. This works best with GFP-Lifeact labelled cells. Doing this by fluorescence is challenging as the cells stop phagocytosis when exposed to too much light, so balancing exposure rate with phagocytosis rate is difficult. Fluorescence imaging can be very challenging with axenically grown cells. Cells rapidly round up when exposed to fluorescent light. It is best for any fluorescence imaging experiment to starve the cells in buffer for at least 3 hours to allow macropinosomes containing HL5 to be exported out of the cell before light exposure. Alternatively, the cells are less sensitive to light exposure if grown on live or heat killed bacteria (see bacterial growth protocol on dictyBase).

\section{Cytoskeletal inhibitors}

We have used latrunculin, nocodazole and other cytoskeletal inhibitors to look at changes in cell behavior following drug treatment. This is especially interesting with cells expressing GFP-tubulin or GFP-lifeact. This allows students to ask whether the effect of the drug on the cytoskeleton parallels the phenotypic effect on cell behaviour which highlights the potential difference between primary targets and off-target effects.

\section{Cell adhesion to substrates}

With a shaker platform and microscope it is possible to do simple adhesion assays. Cells are plated on various substrates for various amounts of time. Then the plates are put on a gyrator shaker at low rpm and the supernatant sampled at intervals. As cells detach, the concentration in the supernatant increases so the detachment rate is easily measured with a hemocytometer.

\section{Phototaxis of slugs}

It is easy to make a light box for unidirectional light and plate amoebae so they form slugs which migrate toward the light. Mutant cell lines or soil isolates can be compared to NC4, which is the standard wild-type strain of Dictyostelium.

\section{Scenario 2: Pomona College Introduction to Cell Biology and Cell Chemistry Lab (Biol41C)}

A semester-long introductory cell biology and basic biochemistry course with three 1-hour sessions of classroom instruction and one 3.75-hour lab per week. The approximately 110 students each year are divided between four or five sections each with its own instructor. Three-quarters are freshmen. The course is run by the instructor plus one TA with some occasional help from a secondary instructor who is also responsible for course organization and lab prep. The Dictyostelium folate-mediated under-agarose chemotaxis module fills the last seven weeks of the semester (Moore, et al., 2018).

\section{Motivation}

Our department has a long-standing tradition of incorporating independent projects into almost every lab course. While the independent project, or inquiry-based, model does not have the same impacts as working in research labs or a classroom undergraduate research experience (CURE), this model incorporates many of the benefits of these experiences in a way that can be the same from year to year (Auchincloss et al., 2014; Beck et al., 2014). Until seven years ago, our introductory cell biology lab did not incorporate microscopy and hardly utilized living things, both of which we saw as major shortcomings. I explored what many other colleges were doing, and little seemed to match our limitations and our desire to have a rich set of potential independent projects that our students would be able to explore. However, Dictyostelium chemotaxis seemed to create such an opportunity, since students could explore the process by altering or perturbing the chemoattractant, signal transduction, cytoskeletal components, surface adhesions, and a number of food and environmental components that have been shown in other systems to slow cell motility.

\section{Resources}

With a modicum of good equipment and some creative modifications, the Dictyostelium folate under-agar chemotaxis assay (Laevsky and Knecht, 2001) has allowed us to create the desired experimental paradigm. For the first two years, we ran this lab as an endpoint assay using dissecting microscopes. Then we combined $4^{\text {th }}$-generation iPod Touches with our 60-year old American Optics upright compound microscopes to capture time-lapse 
Fig. 5. (A) iPod Touch mounted on an American Optics compound microscope with a $3 D$ printed adapter with a wormgear clamp. (B) Image of cells migrating upward toward the folate source.
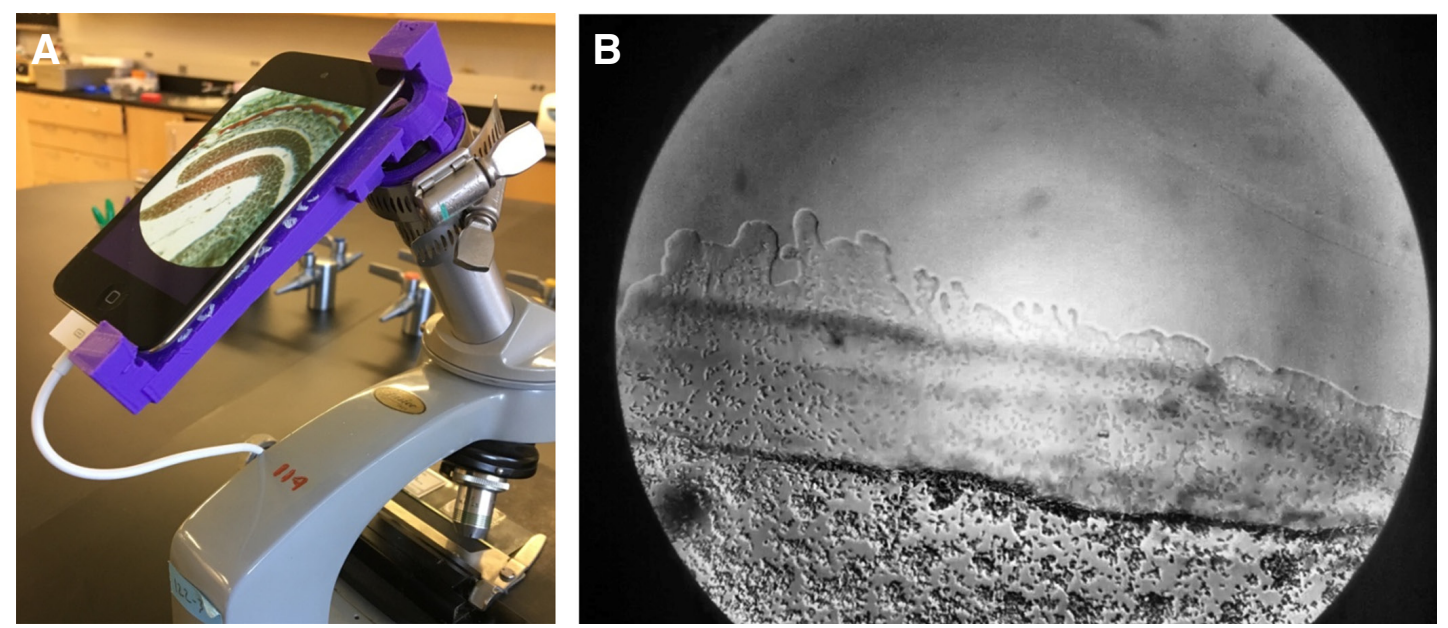

microscopy of Dictyostelium motility. For the next two years we used commercially available adaptors to mount the iPods to the microscopes but students and some faculty found them exceedingly cumbersome to use. Starting three years ago, we designed 3D-printed adaptors (Fig. 5 and Supplemental Movie 4) which are much easier to use.

The labs are set up, coordinated, maintained, and developed by a small group of paid undergraduates and the instructor. For us, setting up a lab for 15 groups with typically two students per group takes less than two hours of combined undergraduate and more expert labor. There are three predominant activities: pouring agarose plates, providing reagents for the independent projects, and preparing and growing the cells. Note that we grow the wildtype, non-axenic NC4 strain, and feed them E. coli rather than growing an axenic strain in rich media. More about this choice can be found in the section below on using Dictyostelium with little or no experience. Protocols for lab preparation, the student protocol, useful videos, PowerPoint files, and files for 3D-printing adaptors can be found at http://pages.pomona.edu/ jm014747/ teaching/dicty.html

This half-semester module costs about $\$ 25$ to $\$ 30$ per student group. With the aid of a peristaltic pump for plate pouring, large cultures, and more limited choices for student projects, I estimate one could set up this lab for 100 student groups with less than four hours of labor.

\section{Learning goals}

This module follows one on enzymology with the same independent project model. During that module, we have already covered and practiced searching the scientific literature, pulling relevant information from papers, proposing hypothesis-driven experiments with appropriate controls, calculating dilutions and unit conversion, and presenting data. The Dictyostelium module gives the students another opportunity to practice these conceptual skills as well as learning to deal with variance and outliers, and interpreting and analyzing data of their own.

Regarding laboratory skills learned in the Dictyostelium module, students practice accurate pipetting, perform dilutions, learn to use compound microscopes, use a hemocytometer to identify live and dead cells and calculate cell densities, understand the need to calibrate an instrument, further develop good notebook skills, gain more practice spatially organizing themselves at the bench and managing their time, and need to manage many sequential successes to realize a larger final goal. We also introduce two computational skills - learning to use basic spreadsheet functionalities and executing and interpreting t-tests.

\section{Timeline \& experiments}

Our lab periods are 3-hours-45-minutes, but since most students do not take all the allotted time, more typical three-hour periods should suffice. Also, some of these seven lab periods are helpful but unessential or could be done as homework, so this sequence can be shortened.

\section{Week 1: 20 minutes to 1.5 hours}

A short lecture on Dictyostelium, chemotaxis, and cell motility. Some instructors incorporate this material into classroom material presented outside of lab time or into the second lab period.

\section{Week 2: 3 hours}

The students perform the under-agarose chemotaxis assay and make time-lapse videos. After a lab quiz, there is a brief pre-lab lecture about the day's lab. The students set up the assay with pre-prepared agarose plates, cells, and folate. While waiting 80 minutes for chemotaxis to become robustly apparent, they familiarize themselves with the microscopes and the methods of video capture, count cells in a hemocytometer, and take videos of a slide micrometer to later calibrate their videos. Video capture is with an iPod Touch using Lapse It Pro software (http://www.lapseit. com), although the built-in iOS time-lapse feature also works. Students then fully fill the wells on their plates, place a coverslip over them, and invert the plates with surface tension holding the coverslip in place. Last, they take two 10-minute time-lapse videos of chemotaxis.

\section{Week 3: 2 hours}

The students analyze their videos from the previous lab. Lab starts with a quiz and brief pre-lab lecture. Students track cells from their videos using ordinary video player apps and screen coordinates, which they then record in spreadsheet software and use to calculate various quantitative motility measures (Meijering et al., 2012). Note that we do not use ImageJ. This is an excuse to have students learn basic spreadsheet manipulations if they have not learned this skill elsewhere. The HHMI Biolnteractive 
Spreadsheet Tutorials at https://www.hhmi.org/biointeractive/ spreadsheet-data-analysis-tutorials are marvelous. Students then use a t-test to compare some of their results with those of another lab group. This is lab semi-optional; due to a weekday holiday, we often turn this into an extensive homework assignment with drop-in help sessions instead of taking up a lab period.

\section{Week 4: 15 to 20 minutes per student group}

Individual groups and an instructor discuss their proposed independent projects. During these meetings, we discuss their hypothesis \& predictions, appropriate controls, the motility measures they want to use and why, complications such as solvent controls, and the feasibility of the experiment. Cost, toxicity, chemical availability, lab time, and poor experimental design can all cause a group to need to explore new ideas. Students turn in what we call their project outline.

\section{Week 5: 3 hours. Independent projects, week 1}

Students perform the control and experimental under-agarose assays using the same tools as in week 2 using solutions of their special reagents provided by the instructor. They turn in their project proposal which should be more complete and detailed than the outline. Data analysis should be done outside of lab time.

The following list of reagents requested in spring of 2016 illustrates the many ways you can perturb the assay to explore many different hypotheses. Most of the ideas were arrived at by students looking at the primary literature. Many of these reagents are quite benign and others are rather toxic. However, we consider most reagents reasonably safe when provided to the students in solution, in the quantities they need (which are usually tens of microliters), and with appropriate precautions and personal protective equipment.

\begin{tabular}{|c|c|}
\hline caffeine & LY-294,002 \\
\hline 8-СРT-Cyclic AMP & plastics of differing hydrophobicity \\
\hline Polysphondylium & temperature \\
\hline $\begin{array}{l}\text { decaf green tea } \\
\text { green tea }\end{array}$ & $\begin{array}{l}\text { formaldehyde, highly dilute } \\
\text { ammonium chloride }\end{array}$ \\
\hline $\mathrm{MgCl}_{2}$ & curcumin \\
\hline colcemid & nocodazole \\
\hline cAMP & arachidonic acid \\
\hline naringenin & buffers at pH's $5.4,6.1, \& 7.1$ \\
\hline epigallocatechin gallate & cytochalasin D \\
\hline zoledronic acid & phenylthiocarbamide \\
\hline ibuprofen & naringenin \\
\hline capsaicin & latrunculin A \\
\hline starving Dictyostelium & wortmannin \\
\hline 2,3-Butanedione monoxime & potassium propionate \\
\hline catechin & pterine \\
\hline cycloheximide & concentrated folate \\
\hline & \\
\hline
\end{tabular}

Week 6: 3 hours. Independent projects, week 2

They perform more control and experimental under-agarose assays. This second week is quite valuable, since if they make a mistake in the first week, this allows them to correct it. If all went smoothly the first week, this is an opportunity to see if the result repeats or explore a variant of their original experiment. There is a brief lecture about their project presentations next week.

\section{Week 7: variable depending on the size of the class}

Eachstudent grouphas 8-minutes to present their experimental rationale, motivation, results, conclusions, and future experiments.

\section{Scenario 3: Loras College Cellular and Molecular Biology (BIO 410)}

A semester-long upper-level general cell biology course with three 1-hour sessions of flipped-classroom information/discussion and one 3-hour lab per week. Around 30 students, primarily juniors and seniors, divided between two lab sections. The course instructor is responsible for both the class and the lab session and much of the lab set-up. The Dictyostelium chemotaxis experiment is one of about six multi-week labs done over a 14-week semester.

\section{Motivation}

At Loras College in Dubuque, lowa the under-agarose chemotaxis assay has been modified for a small upper-level Cellular and Molecular Biology lab class using one research-grade microscope. There are 10-12 three-person student groups every spring semester. For this experiment, the student groups choose two different concentrations of folic acid to use in the under-agarose migration assay, and then must do the calculations to dilute the stock solution and set up their experiment themselves with Dictyostelium already prepared and counted for them. I choose to provide the cells for them because this is a short lab sequence as part of a longer semester of labs, and teaching 30 students to do cell culture for one experiment is not practical.

Giving students even a small opportunity to pick the experimental concentrations of folic acid greatly increases their interest in the results compared to telling them which concentrations to try. As someone new to Dictyostelium, but familiar with human neutrophils when I started using this lab with my students, I do not worry about the fact that the Dictyostelium might not be all experiencing the same concentration of folic acid. What is most important is that the students manipulate some parameter and then be able to quantitatively compare their experimental data.

\section{Resources}

Funds are not available to allow students to independently choose any hypothesis they want to investigate, and no help is available for cell culturing or plate-pouring, so the lab is very streamlined. The groups each sign up for an hour time slot for the research-grade Olympus IX-81 microscope and XM-10 camera. They then set up their underagarose plates and then let them incubate for 1-3 hours. They later return for their time slot and take two 10-15 minute movies of each of their assay plates. Because there is only one video microscope, some lab groups do this experiment outside of the normal 3-hour lab schedule. This does require the one lab instructor to be involved in helping the students intermittently much of the week during data collection. However, most of the students are upper-level juniors and seniors who are fairly comfortable in a lab setting and do not need much assistance as they follow the detailed experimental protocol. Since the lab with the microscope is next to the instructor's office, this causes minimal interruption with other work. 


\section{Learning goals}

Students learn about a complicated cell process in the lecture and then visualize it in this hands-on investigation, which helps with retaining an understanding of the proteins involved.

Data quantification and analysis is another important learning goal. Therefore, cell tracking using the MTrackJ plug-in for Image $\mathrm{J}$ is a part of the experiment. Initially, our engineering department designed adjustable 3D-printed microscope-adapters but the variability of cell phone camera quality and the quality of the student microscopes available meant that the year this was tried the movies obtained using this method were not of high enough quality for cell tracking.

Finally, figure creation and scientific writing in the style of a journal article also is part of this lab module.

\section{Timeline \& experiments}

The first week of this lab module is when students do the under-agarose plate set-up and then capture movies at various times during the week. In the next week's lab, the students track the cells in the movies using MTrackJ to quantify their behavior, and the following week they turn in a report with a Results section with three figures (a montage from their movies, a graph of the cell speeds, and a graph of the cell directional persistence), and a Discussion section. Overall this lab occupies 2 weeks of a 14-week semester-long course.

\section{Tips for instructors with little to no experience working with Dictyostelium}

Using a new model organism in a lab course can be daunting. What if my zebrafish do not breed? What if all my Arabidopsis succumb to virus a few days before the lab? "I was told this was easy, but what was it that the expert forgot to tell me?" Two of us had no experience with Dictyostelium until several years ago when we began teaching these labs and we can say that working with Dictyostelium is genuinely quite straightforward. Still, here we share some issues that have arisen and how we solved them.

\section{Choosing a parental cell line and growth method}

A key first decision is what will be your primary method for growing Dictyostelium, and subsequently what will be your default wild-type strain. All Dictyostelium cell lines will grow on bacteria as a food source, but only axenic strains will grow in broth media. If you are starting to work with Dictyostelium and have mammalian cell culture experience, it is easy and comforting to treat them basically like mammalian cells and grow them on plastic Petri dishes (or shaking suspension) in media. Axenic strains have been mutated to induce constitutive macropinocytosis allowing sufficient media uptake allow cell growth. The non-defined complex media (HL5) can be purchased from Formedium Inc. or made from powdered reagents. There is also a defined media (FM) that can be used for cell growth.

If you choose this option, be sure to choose an axenic strain, such as $A X 2, A X 3, A X 4$ or NC4A2. These strains are all equivalent for the purposes of these lab experiments except that NC4A2 is more motile than the others. These strains have the advantage that nearly all mutant strains are derived from axenic parental strains, making experimental comparisons possible. Following the basic instructions on dictyBase will allow you to keep them at the right density and take care of them correctly. One natural question arising from experience with mammalian cells is what does one use to harvest cells from the Petri dish? EDTA? Trypsin/EDTA? It turns out that Dictyostelium are even simpler than that: rapidly expelling the media from a $10 \mathrm{ml}$ pipette (triturating) is sufficient to wash the cells off the bottom of a petri dish. Also, any type of plastic dish will work equivalently. You do not need tissue culture treated plastic dishes.

If you choose to work with wild isolates (non-axenic cells), you will have to feed them $E$. coli or Aerobacter aerogenes in simple buffered solutions in either stationary dishes or with some agitation. Axenic strains can also be grown this way. One advantage of this method of growth is that contamination is not an issue. When running a lab with many students, several instructors, and a tight schedule, everything one can easily do to increase reliability is invaluable. Without a sterile hood nearby and using what some call "semi-sterile technique"-working with sterile solutions, plastics, and glassware but in the open air - we have found that contamination has not been a problem. Hence, this approach is more reliable and is easier. Second and anecdotally, one of us thinks that wild-type NC4 cells, begin migrating faster in a chemotaxis assay when fed bacteria, though this has not been systematically analyzed. Last, if you need large quantities of cells quickly, the doubling time of NC4 and other strains on bacteria is 4-5 hours, while the doubling time of axenic cells in media is $8-12$ hours.

\section{Temperature control}

Dictyostelium can be grown at room temperature, but if your rooms tend to fluctuate much or they are simply generally warm, keep in mind that Dictyostelium growth slows above $25^{\circ} \mathrm{C}$, heat shock begins to set in at about $27^{\circ} \mathrm{C}$ and cells will die at $30^{\circ} \mathrm{C}$. A refrigerated incubator is important for maintaining cells if temperature regulation is unreliable while a thermoelectric wine cooler can be used an inexpensive alternative. Temperature control can also be helpful when the cells are doubling four to six times per day, as that extra control leads to more predictable outcomes.

\section{Chemotaxis assay tips}

In setting up this assay, sometimes the plates will absorb solutions from the wells, which can leave your unfortunate Dictyostelium cells dry. This seems to be caused by the plates drying out even the slightest. One can prevent this by using plates poured on the same day. Another solution is to preincubate the plates with buffer or water for a short period of time before the experiment is set up.

Be sure that the thickness of the plastic of your Petri dishes is well under the working distance of the objectives you plan to use. Inverted microscopes usually have long working distance objectives, but upright microscopes are often equipped with short working distance objectives that can be limiting in the Scenario 2 upside down dish protocol. Petri dish plastics can vary $10-20 \%$ between manufacturers, so if the average plastic thickness and working distance are close, you may find that you might not always be able to use some objectives. Having or borrowing a set of calipers can be very valuable.

Last, if you only have bright-field optics, individual Dictyostelium cells are fairly low contrast, so it is somewhat challenging for students to find migrating cells. Closing the field diaphragm or using slightly oblique lighting can help to increase contrast. Still, with patience and good instruction, they will learn to manage well. 


\section{Cutting costs}

While Dictyostelium are an inexpensive model organism to work with, it is still useful to minimize costs whenever possible, particularly with a small budget for lab courses and less lab technician assistance.

1. Glass pipettes are an up-front investment, but if funds can be found for them once, it eliminates the expense of constantly buying plastic pipettes for cell line maintenance.

2. Reagents, likeAlexa-fluor-phalloidin, are expensive, but last for many years because so little is used for each experiment. Doing the same lab multiple years in a row is more cost-effective. The same applies to many reagents needed for student-initiated hypothesis driven research, since many students will arrive at the same hypothesis.

3. Disposable hemocytometers are about 200-fold less expensive than traditional glass ones which will inevitably be broken. Some designs of the disposable versions can also be reused a few times.

4. Many glass and metal food containers are autoclavable and far cheaper than autoclavable glassware and other products. Generally speaking, if it can be used for canning in a pressure cooker, it can be autoclaved. Lids without seals are preferable, since after enough times through the autoclave, the seals peel off.

\section{Conclusion}

Dictyostelium provides a breadth and depth of possible applications and ease of use which is tremendously powerful in cell biology teaching labs. Presented here are but the fraction about which we are most familiar. Other instructors are utilizing Dictyostelium in a variety of types of experiments which are available on dictyBase. Perhaps ideas for effective teaching labs have impressed you as you read other articles in this Special Issue on Dictyostelium. As we collectively learn and technologies develop, we will develop new labs and tweak old ones to adapt and teach better. The simple yet versatile Dictyostelium model system will continue to offer a wide range of possibilities for laboratory courses.

\section{References}

AUCHINCLOSS, LC, LAURSEN, SL, BRANCHAW, JL, EAGAN, K, GRAHAM, M HANAUER, DI, LAWRIE, G, MCLIONN, CM, PELAEZ, N, ROWLANDS, S, TOWNS, M, TRAUTMANN, NM, VARMA-NELSON, P, WESTON, TJ, DOLAN, EL (2014) Assessment of Course-Based Undergraduate Research Experiences: A Meeting Report, CBE Life Sci Educ. 13: 29-40.

BECK, C, BUTLER, A, DA SILVA, KB (2014) Promoting Inquiry-Based Teaching in Laboratory Courses: Are We Meeting the Grade? CBE Life Sci Educ. 13: 444-452.

BOZZARO, S. (2019). The past, present and future of Dictyostelium as a model system. Int. J. Dev. Biol. 63 (DOI: https://doi.org/10.1387/ijdb.190128sb).

LAEVSKY, G AND KNECHT, DA (2001) Under-agarose folate chemotaxis of Dictyostelium discoideum amoebae in permissive and mechanically inhibited conditions. BioTechniques 31: 1140-1149.

MEIJERING, EO, DZYUBACHYKM I, SMAL, I (2012) Methods for cell and particle tracking. Methods Enzymol. 504: 183-200.

MOORE, JE, PETREACA ML, KNECHT DA (2018) Tested studies for laboratory teaching, Proceedings of the 39th Conference of the Association for Biology Laboratory Education. 39: 13.

ROMERALO, M., SKIBA, A., GONZALEZ-VOYER, A., SCHILDE, C., LAWAL, H., KEDZIORA, S., CAVENDER, J. C., GLÖCKNER, G., URUSHIHARA, H. AND SCHAAP, P. (2013) Analysis of phenotypic evolution in Dictyostelia highlights developmental plasticity as a likely consequence of colonial multicellularity. Proc Biol Sci 280: 20130976. 


\section{Further Related Reading, published previously in the Int. J. Dev. Biol.}

The teaching of Developmental Biology in Spain: future challenges

Manuel Marí-Beffa

Int. J. Dev. Biol. (2009) 53: 1245-1252

https://doi.org/10.1387/ijdb.082612mm

Teaching and research on Developmental Biology in Portugal

Sólveig Thorsteinsdóttir, Gabriela Rodrigues and Eduardo G. Crespo

Int. J. Dev. Biol. (2009) 53: 1235-1243

https://doi.org/10.1387/ijdb.082692st

History and status of embryology and developmental biology at Polish Medical Faculties and Schools Hieronim Bartel

Int. J. Dev. Biol. (2008) 52: 141-146

https://doi.org/10.1387/ijdb.082605hb

Virtual labs: a substitute for traditional labs?

Rebecca K Scheckler

Int. J. Dev. Biol. (2003) 47: 231-236

http://www.intjdevbiol.com/web/paper/12705675

Using models to enhance the intellectual content of learning in developmental biology John C McLachlan

Int. J. Dev. Biol. (2003) 47: 225-229

http://www.intjdevbiol.com/web/paper/12705674

Course enhancement: a road map for devising active-learning and inquiry-based science courses

William S Harwood

Int. J. Dev. Biol. (2003) 47: 213-221

http://www.intjdevbiol.com/web/paper/12705672

My perpetual cycle: from student to researcher to teacher to student ...

Robert Vignali

Int. J. Dev. Biol. (2003) 47: 203-211

http://www.intjdevbiol.com/web/paper/12705671

Four decades of teaching developmental biology in Germany

Horst Grunz

Int. J. Dev. Biol. (2003) 47: 193-201

http://www.intjdevbiol.com/web/paper/12705670

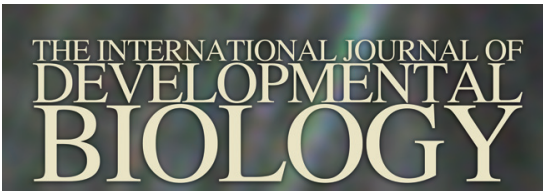

Volume 56 Nos. $1 / 2 / 3$

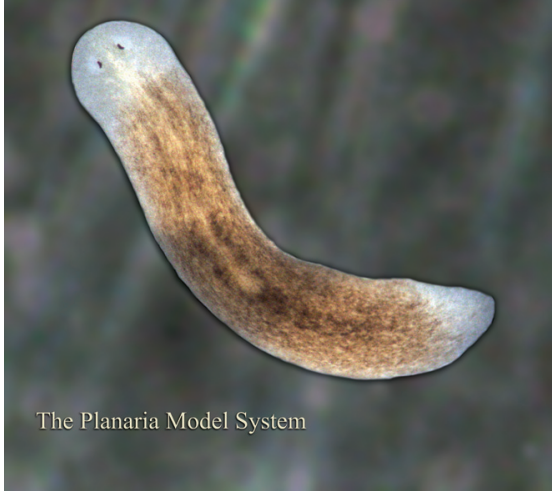

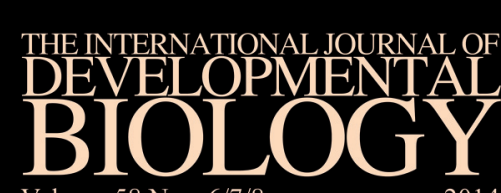

Volume 58 Nos. 6/7/8

2014

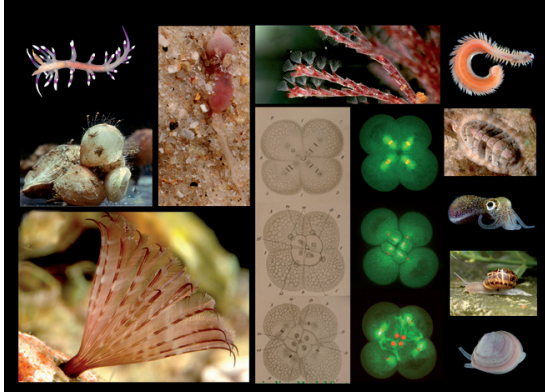

Spiralian Model Systems
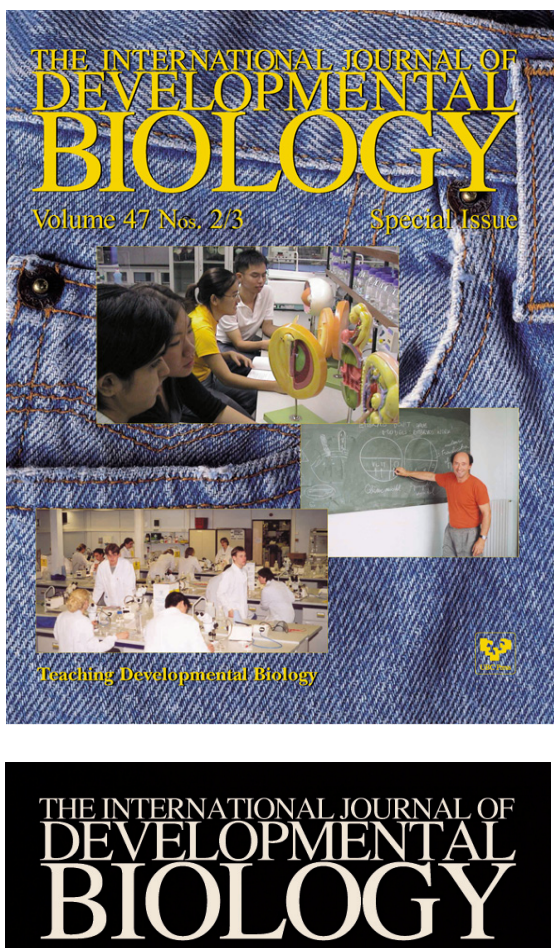

Volume 61 Nos. 10/11/12

Special Issue

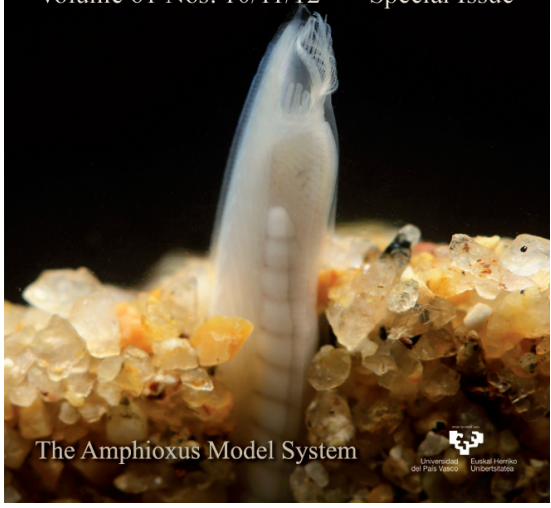

